\title{
About the Rigid Slab Hypothesis in High-Rise Building Duan Jin ${ }^{1, a}$, Chen Xiao-ming ${ }^{1}$, Li Yun-gui ${ }^{1}$ \\ ${ }^{1}$ China State Construction Technical Center, Beijing, 101300, PR China \\ a duanjin78@126.com
}

Key words: rigid slab, elastic slab, FEA, high-rise building, ISSS

Abstract: In this paper, the rigid slab hypothesis, which is widely used in high-rise buildings, would be discussed. The modal analysis results for two building structures would be presented and compared based on the ISSS [1-4], with and without rigid slab hypothesis respectively. It could be observed from the present computing results that: (1) there are only slight difference between the natural frequencies of elastic slab model and rigid slab model; (2) while there are large difference between the effective mass coefficients for one of the buildings. So the following conclusion could be obtained that the hypothesis of rigid slab is not adaptive to all kinds of high-rise buildings and for some structures the elastic slab model also deserves attention, although its computational scale is much larger than that of rigid slab model.

\section{Introduction}

To satisfy the engineering requirements of high performance simulation (HPS), the authors [1-4] have developed an integrated simulation system for building structures, or simply ISSS for short, which is an integration of traditional design softwares, such as PKPM, ETABS, MIDAS, YJK, etc., and general FEA softwares, such as ABAQUS, ANSYS, etc., together with abundant secondary software development, such as data automatic transformation from the structural model to finite element analysis (FEA) model [2,3], data automatic evaluation and statistics according to the building structure specification, and the additional parallel FEA computing kernel developed specially for the building structures [4].

In this paper, the rigid slab hypothesis, which is widely used in high-rise buildings, would be discussed. The modal analysis results for two building structures would be presented and compared based on the above ISSS, with and without rigid slab hypothesis respectively. It could be observed from the computing results that: (1) there are only slight difference between the natural frequencies of elastic slab model and rigid slab model; (2) while there are large difference between the effective mass coefficients for one of the buildings. So the following conclusion could be obtained that the hypothesis of rigid slab is not adaptive to all kinds of high-rise buildings and for some structures the elastic slab model also deserves attention, although its computational scale is much larger than that of rigid slab model.

\section{Consideration about the rigid slab hypothesis in ISSS}

The hypothesis of rigid slab could be described as that the in-plane stiffness of the slab is infinite large while the out-plane stiffness is infinite small. Due to the fact that the slabs usually connect with shear walls and beam-components, the boundary nodes lying at the connecting lines of shear walls and slabs shown in Fig. 1 would satisfy the above hypothesis. That is to say all of those boundary nodes at the same floor have the same horizontal displacements and share the same angle displacement about z-axis. In another word, only one of the boundary nodes at the same floor could serve as the master node, while all of the other nodes should serve as the slave nodes. If node 1 is assumed as the master node, then all of the others, e.g. node $\mathrm{i}$, are slave nodes. The displacement relationship of the master node and slave nodes could be described by Fig. 2 and the following Eq. 1 (see References [5-7] for details) are adopted in ISSS [1-4] to consider the effects of rigid slab. 


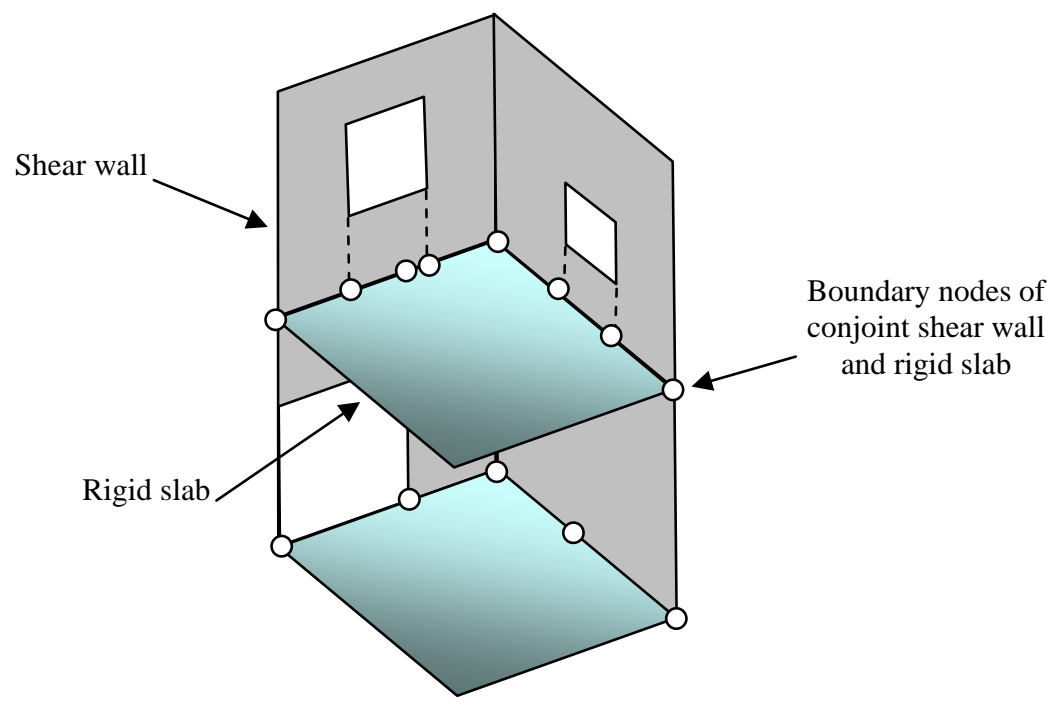

Figure 1 Illustration of rigid slab

$$
u_{i}^{x}=u_{1}^{x}-r_{1 i}^{y} \theta_{1}^{z} ; \quad u_{i}^{y}=u_{1}^{y}+r_{1 i}^{x} \theta_{1}^{z} ; \quad \theta_{i}^{z}=\theta_{1}^{z}
$$

Where $r_{1 i}^{x}$ and $r_{1 i}^{y}$ represent the projections of vector $\mathbf{r}_{1 i}$ along axes $\mathrm{x}$ and $\mathrm{y}$ respectively, $u_{i}^{x}$ and $u_{i}^{y}$ represent the components of displacement $\mathbf{u}_{i}$ along axes $\mathrm{x}$ and $\mathrm{y}$ respectively, and $\theta_{i}^{z}$ represent the component of angle displacement $\boldsymbol{\theta}_{i}$
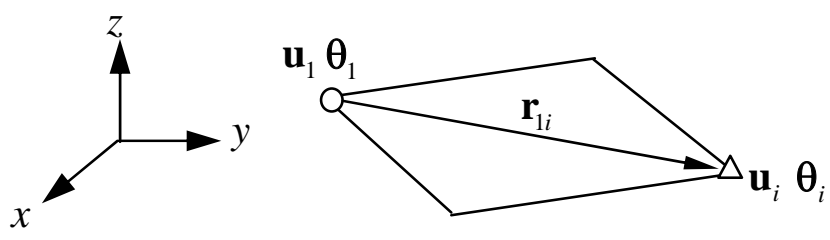

Figure 2 Constraints of rigid slab

\section{Comparison of results with elastic slab and rigid slab hypothesis}

To examine the different effects of rigid slab hypothesis for different complex building structures, two examples of multi-tower building are presented and discussed in the following.

\subsection{Comparison of results with example one}

Fig. 3 shows another example of multi-tower building. The computing scale with elastic slab and rigid slab hypothesis are shown in Table 1, from which it can be seen that the computing scale of elastic slab model is much larger than that of rigid slab model. The natural frequencies and effective mass coefficients computed with elastic slab model and rigid slab hypothesis are shown in Table 2 and Fig. 4. Obviously, the results of frequency are very close, with the maximum error of $4 \%$ approximately, while the results of effective mass coefficient are very different, with the maximum error of $40 \%$ approximately. So for this building structure, the difference between elastic slab model and rigid slab model could not be ignored. In another word, the rigid slab hypothesis is not, at least not very, suitable for this building structure. 


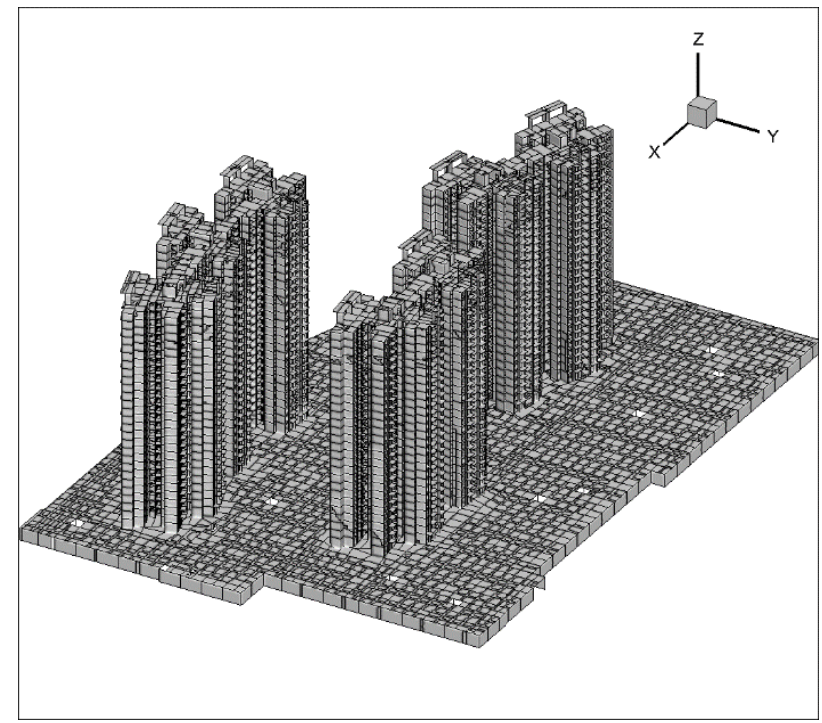

Figure 3 Model of example one

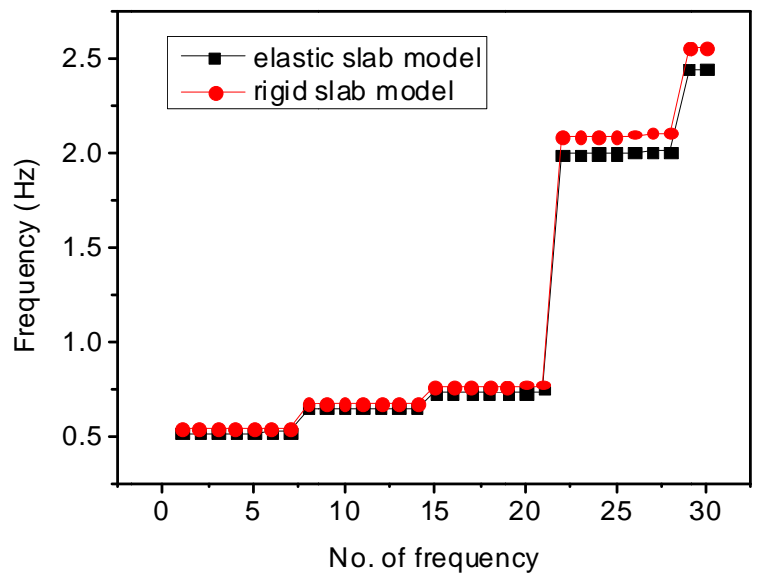

Figure 4 Natural frequencies with elastic slab and rigid slab hypothesis for example one

Table 1 Computing scale with elastic slab and rigid slab hypothesis for example one

\begin{tabular}{|l|l|l|}
\hline & Rigid slab model & Elastic slab model \\
\hline Dofs (million) & 0.46 & 2.4 \\
\hline Dynamic dofs & 633 & 800,000 \\
\hline
\end{tabular}

Table 2 Computing results with elastic slab and rigid slab hypothesis for example one

\begin{tabular}{|l|l|l|l|l|}
\hline \multicolumn{2}{|c|}{} & Rigid slab model & Elastic slab model & Computing error \\
\hline \multirow{2}{*}{ Frequency (Hz) } & $1^{\text {st }}$ & 0.54 & 0.51 & $4.4 \%$ \\
\cline { 2 - 5 } & $30^{\text {th }}$ & 2.55 & 2.44 & $4.3 \%$ \\
\hline \multirow{2}{*}{ Effective mass coefficient } & $0.84(\mathrm{x})$ & $0.49(\mathrm{x})$ & $42 \%$ \\
\cline { 3 - 5 } & $0.90(\mathrm{y})$ & $0.51(\mathrm{y})$ & $43 \%$ \\
\hline
\end{tabular}

\subsection{Comparison of results with example two}

Fig. 5 shows another example of multi-tower building. The computing scale with elastic slab and rigid slab hypothesis are shown in Table 3 . The natural frequencies and effective mass coefficients computed with elastic slab model and rigid slab hypothesis are shown in Table 4 and Fig. 6 . Obviously, the results are very close, with the maximum error of $8 \%$ approximately. For this building structure, the difference between elastic slab model and rigid slab model could be ignored. In another word, the rigid slab hypothesis is suitable for this building structure. 


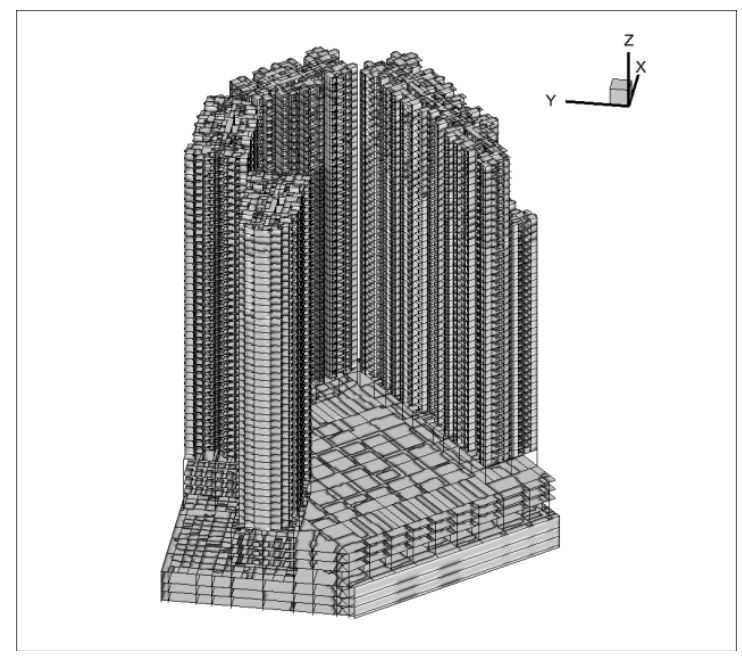

Figure 5 Model of example two

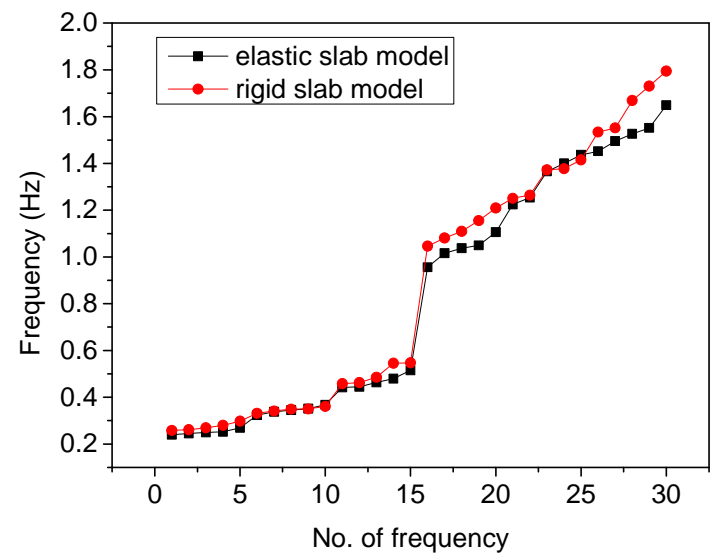

Figure 6 Natural frequencies with elastic slab and rigid slab hypothesis for example two

Table 3 Computing scale with elastic slab and rigid slab hypothesis for example two

\begin{tabular}{|l|l|l|}
\hline & Rigid slab model & Elastic slab model \\
\hline Dofs (million) & 0.6 & 1.5 \\
\hline Dynamic dofs & 690 & 500,000 \\
\hline
\end{tabular}

Table 4 Computing results with elastic slab and rigid slab hypothesis for example two

\begin{tabular}{|l|l|l|l|l|}
\hline \multicolumn{2}{|c|}{} & Rigid slab model & Elastic slab model & Computing error \\
\hline \multirow{2}{*}{ Frequency (Hz) } & $1^{\text {st }}$ & 0.26 & 0.24 & $7.7 \%$ \\
\cline { 2 - 5 } & $30^{\text {th }}$ & 1.79 & 1.65 & $7.8 \%$ \\
\hline \multirow{2}{*}{ Effective mass coefficient } & $0.60(\mathrm{x})$ & $0.61(\mathrm{x})$ & $1.7 \%$ \\
\cline { 3 - 5 } & $0.62(\mathrm{y})$ & $0.63(\mathrm{y})$ & $1.6 \%$ \\
\hline
\end{tabular}

\section{Conclusions}

The rigid slab hypothesis, which is widely used in high-rise buildings, has be discussed in this paper. The modal analysis results for two building structures are presented and compared based on the ISSS [1-4], with and without rigid slab hypothesis respectively. It could be observed from the present computing results that: (1) there are only slight difference between the natural frequencies of elastic slab model and rigid slab model; (2) while there are large difference between the effective mass coefficients for one of the buildings. So the following conclusion could be obtained that the hypothesis of rigid slab is not adaptive to all kinds of high-rise buildings and for some structures the elastic slab model also deserves attention, although its computational scale is much larger than that of rigid slab model. 


\section{Reference}

[1] J. Duan, X.M. Chen, H. Qi \& Y.G. Li. An Integrated Simulation System for Building Structures. Applied Mechanics and Materials, Vol.3(2014), p.33-36

[2] J. Duan, X.M. Chen, H. Qi \& Y.G. Li. An Automatic FE Model Generation System Used for ISSS. Civil Engineering and Urban Planning, Vol.3(2014), p.33-36

[3] J. Duan, X.M. Chen, H. Qi \& Y.G. Li. Boundary-Constraint Meshing Based on Paving Method. Applied Mechanics and Materials, Vol.627(2014), p.262-267

[4] J. Duan, X.M. Chen, H. Qi \& Y.G. Li. A Parallel FEA Computing Kernel for ISSS. Green Building, Materials and Civil Engineering, Vol. 4(2014), p. 131-135

[5] K.J. Bathe. Finite Element Procedures. New Jersey: Prentice Hall. (1996)

[6] R.D. Cook. Finite Element Modeling for Stress Analysis. New York: John Wiley \& Sons, INC. (1994)

[7] X.C. Wang. Finite Element Method. Beijing: Tsinghua University Press. (2003, in Chinese) 